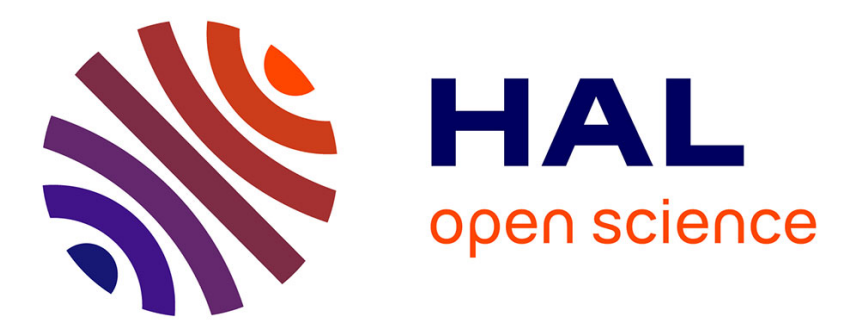

\title{
Colonic myoelectrical activity and propulsion in the dog.
} Jean Fioramonti, Rafael Garcia Villar, Lionel Bueno, Y. Ruckebusch

\section{To cite this version:}

Jean Fioramonti, Rafael Garcia Villar, Lionel Bueno, Y. Ruckebusch. Colonic myoelectrical activity and propulsion in the dog.. Digestive Diseases and Sciences, 1980, 25 (9), pp.641-646. hal-02731489

\section{HAL Id: hal-02731489 \\ https://hal.inrae.fr/hal-02731489}

Submitted on 2 Jun 2020

HAL is a multi-disciplinary open access archive for the deposit and dissemination of scientific research documents, whether they are published or not. The documents may come from teaching and research institutions in France or abroad, or from public or private research centers.
L'archive ouverte pluridisciplinaire HAL, est destinée au dépôt et à la diffusion de documents scientifiques de niveau recherche, publiés ou non, émanant des établissements d'enseignement et de recherche français ou étrangers, des laboratoires publics ou privés.

\section{다(1) (2)}

Distributed under a Creative Commons Attribution - ShareAlikel 4.0 International 


\title{
Colonic Myoelectrical Activity and Propulsion in the Dog
}

\author{
JEAN FIORAMONTI, BS, RAFAËL GARCIA-VILLAR, BS, \\ LIONEL BUENO, DS, and YVES RUCKEBUSCH, DS, DVM
}

\begin{abstract}
Electrical spike activity was recorded on the colon of the dog. The duration of the bursts of the spike was used to divide the spike activity into two different types: long and short spike bursts (LSB and SSB). LSBs lasted from 7 (ascending) to 37. sec (descending) and $S S B$ s lasted about $1 \mathrm{sec}$, independent of the site. These measurements were applied to colons of colostomized dogs for which the colonic transit time was negatively correlated to the LSBs expressed as percent of the time. The effects of high-and low-residue diets were tested. Intake of large amounts of dry food was associated with an increase of the $L S B$ activity. A meat diet was accompanied with an increase of the SSB activity. These results suggest a propulsive effect for the LSBs stimulated by large amounts of colonic contents while the SSB activity may reflect some degree of emptiness.
\end{abstract}

Most of electromyographic studies of the colon concerned recording of slow waves and their analysis. These slow waves are labile and occur at a frequency of 5-8 cycles $\min$ in the conscious dog (1-3). Modifications of slow-wave frequency in the rectosigmoid were recently reported in humans suffering from an "irritable bowel syndrome" (4). In vitro studies have also provided evidence for disturbances of the slow-wave propagation in the case of idiopathic or laxative-induced diarrhea (5).

But the colonic electromyogram exhibits also spike activity. Two kinds of spike activity, long and short spike bursts, were recorded in humans (6) and others species including the $\operatorname{dog}(7,8)$. Modifications of their patterns were described in some cases of diarrhea and constipation (6).

The large-bowel disturbances were chieffy investigated from manometric records (9) and transit time measurements (10). More precisely, no relationships between the myoelectrical activity and the transit time of digesta have been established for the

\footnotetext{
Manuscript received October 22, 1979; revised manuscript received April 1, 1980; accepted April 16, 1980.

From the Department of Physiology, National Veterinary School, 31076 Toulouse, Cedex France.

Address for reprint requests: Dr. J. Fioramonti, Ecole Nationale Vétérinaire 23 chemin des Capelles 31076 Toulouse, France.
}

large bowel as they were for the small intestine (11, 12).

The following experiments were undertaken, first, to describe the pattern of colonic electrical spike activity in normal and colostomized dogs; second, to correlate the pattern and the colonic transit time in colostomized dogs; and third, to evaluate the modifications of the pattern in modified fecal outputs. The fecal output was, respectively, increased and reduced by giving large amounts of dry food and a low-residue diet (bovine meat).

\section{MATERIALS AND METHODS}

Ten female mongrel dogs (14-18 kg), placed in spacious cages and accustomed to receive one daily meal at $1800 \mathrm{hr}$ of $400 \mathrm{~g}$ of canned food (Fido, France) were used. In four animals, a colostomy was performed in the low abdominal region, the colon being sectioned at $9-10 \mathrm{~cm}$ orad to the rectum; these dogs were fitted with a chronic catheter inserted in the colonic lumen at $2 \mathrm{~cm}$ from the ileocolonic junction.

Bipolar intraparietal electrodes made of insulated $\mathrm{Ni} / \mathrm{Cr}$ wire (13) were positioned in the 10 dogs on the ileum at 10 $\mathrm{cm}$ from the ileocolonic junction, on the ascending, descending, and transverse colon at 5, 10, 15, 20, and $25 \mathrm{~cm}$ from the ileocolonic junction, respectively. The last electrode site was located at about $5 \mathrm{~cm}$ from the stomy in the colostomized dogs. 


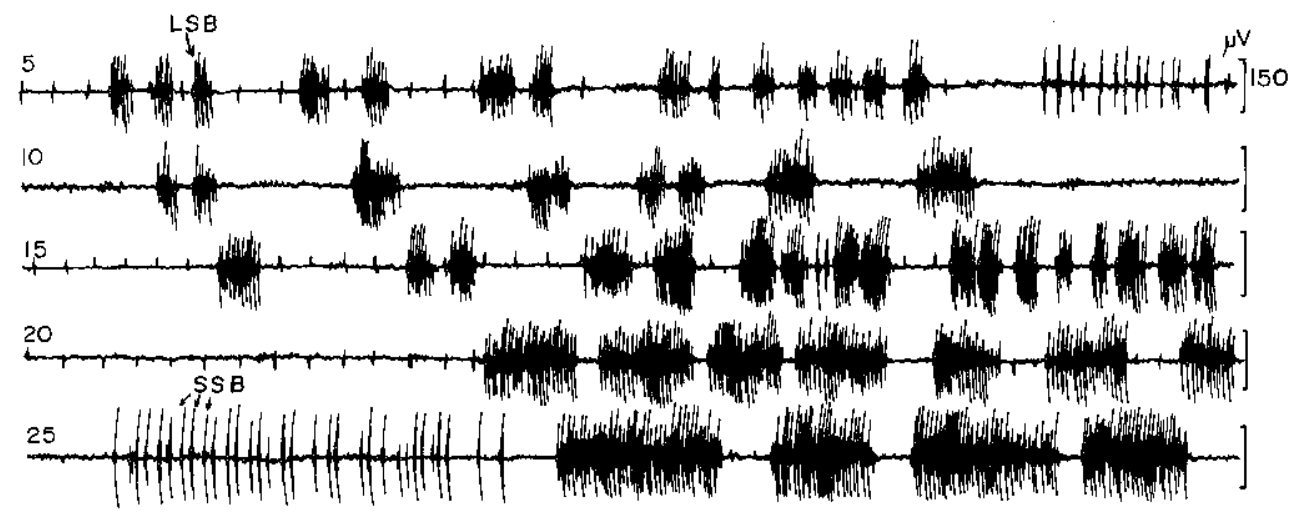

minutes

Fig 1. Electromyogram of the colon in a 12-hr fasted intact dog for five electrode sites at $5,10,15,20$, and $25 \mathrm{~cm}$ from the ileocolonic junction. Long spike bursts (LSB) of about $7 \mathrm{sec}$ duration on the ascending colon and more than $30 \mathrm{sec}$ on the descending colon occurred at 15 to 20-min intervals in series lasting from $5 \mathrm{~min}$ on the ascending colon to $12 \mathrm{~min}$ on the descending colon. Short spike bursts (SSB) of about $1 \mathrm{sec}$ in duration appeared in series localized at one of the electrode sites.

Recordings of colonic electrical activity on an EEG machine (Reega VIII, Alvar, Paris) with a time constant of $0.1 \mathrm{sec}$, began 10 days after surgery and continued periodically between 800 and $1800 \mathrm{hr}$ for $8-12$ weeks. Electromyogram analysis consisted of the determination by visual inspection of the percentage of recording time occupied by long and short spike bursts (LSB and SSB), respectively, in each dog, for three consecutive recording sessions, each lasting $10 \mathrm{hr}$. According to data collected in humans and pigs $(6,7)$, bursts of spikes lasting more than $3 \mathrm{sec}$ were classified as LSB and those lasting less than $3 \mathrm{sec}$ as SSB. The recording time occupied by the spike activity was determined using a curvimeter, by summation of the duration of each individual burst for the LSBs and of the duration of periods during which the SSB activity was not disrupted for more than $10 \mathrm{sec}$. The electrode sites at 5,10 , and $25 \mathrm{~cm}$ from the ileocolonic junction were selected as references for the ascending, transverse, and descending colonic activities. A $\chi^{2}$ Pearson test was performed in each group of dogs (intacts and colostomized) from the total $30 \mathrm{hr}$ of recordings; values are provided as means \pm standard deviation for the two groups of dogs.

Diet. For two weeks, the 6 intact dogs received a standard regimen of $400 \mathrm{~g} /$ day of canned food (Fido: dry matter $21.7 \%$, protein $7.7 \%$, fat $4.5 \%$, carbohydrates $6.8 \%$, minerals $2.6 \%$ ). Then, during a period of two weeks, the diet consisted of a large amount $(500 \mathrm{~g} /$ day $)$ of dry dog food (Royal Canin: dry matter $88 \%$, protein $20 \%$, fat $6 \%$, carbohydrates $55.5 \%$, minerals $6.5 \%$ ); four of the dogs accepted the full ration offered and produced for periods of 2-4 days abundant and soft feces. During a third period of two weeks, only bovine meat ( $300 \mathrm{~g} /$ day) was offered; three of the dogs produced scarce and hard stools during periods of 3-6 days. In all dogs, the daily fecal output and the stool dry matter were measured. However, only the results of dogs presenting a difference in the daily weight of stools of at least $30 \%$ from that observed with the standard diet during 3 successive days were taken into account.

Transit Time. In the 4 colostomized dogs receiving the standard diet, the transit time was measured at intervals of 3 days during EMG recording sessions using phenol red as inert marker. A single bolus ( $1 \mathrm{ml}$ containing $10 \mathrm{mg}$ phenol red) was rapidly injected through the catheter 10 min after the occurrence of a phase of regular spiking activity on the ileal electrode site, that is, in the absence of any major change of the ileal flow of digesta (11). Feces flowing through the colostomy were continuously collected, and their time of appearance after the bolus injection was noted. The concentration of phenol red was determined by a colorimetric method in each sample of feces eliminated at the fistula. The transit time of the bolus was calculated from the time at which feces containing the maximal concentration of phenol red had been collected, as previously described for the small intestine (11). The results were plotted as a percentage of LSB and SSB, and the electrical activity was recorded during each of the 38 measurements of transit time.

\section{Results}

Patterns of Myoelectrical Activity of Canine Colon. In the intact dog fasted for $14 \mathrm{hr}$, long and short spike bursts were recorded in all parts of the colon (Figure 1). Long spike bursts had a mean duration of $6.9 \pm 3.1 \mathrm{sec}$ on the ascending colon at 2 and 5 $\mathrm{cm}$ from the ileocolonic junction, where they appeared at a frequency similar to that of the slow waves but without evident temporal relationships. The duration of LSB was longer on the transverse colon $(14.3 \pm 3.7 \mathrm{sec})$ and lasted $37 \pm 9 \mathrm{sec}$ on the 
Table 1. Characteristics of Electrical Spiking Activity of Ascending (Asc), Transverse (trans), and Descending (Desc) COLON IN INTACT AND COLOSTOMIZED DOGS*

\begin{tabular}{|c|c|c|c|c|c|c|}
\hline & \multicolumn{3}{|c|}{ Intact Dogs $(\mathrm{N}=6)$} & \multicolumn{3}{|c|}{ Colostomized dogs $(\mathrm{N}=4)$} \\
\hline & Asc. & Trans. & Desc. & Asc. & Trans. & Desc. \\
\hline Total spiking activity $\dagger$ & $18.3 \pm 5.4$ & $41.5 \dagger \pm 8.6$ & $47.6 \neq \pm 11.9$ & $18.7 \pm 4.9$ & $39.0 \pm 7.1$ & $40.1 \pm 6.0$ \\
\hline Long spike bursts $\dagger$ & $12.5 \pm 7.8$ & $20.5 \pm 7.7$ & $22.9 \pm \pm 5.5$ & $15.4 \pm 4.2$ & $28.3 \pm 7.0$ & $31.78 \pm 6.6$ \\
\hline $\begin{array}{l}\text { Mean duration of periods (min) } \\
\text { Recurring intervals (min) }\end{array}$ & $4.9 \pm 2.0$ & $\begin{array}{l}7.4 \pm 3.8 \\
28.4 \pm 9.0\end{array}$ & $12.7 \ddagger \pm 5.0$ & $4.3 \pm 3.1$ & $\begin{array}{r}6.9 \pm 2.4 \\
26.5 \pm 5.2\end{array}$ & $8.9 \pm 5.2$ \\
\hline Short spike bursts $\dagger$ & $5.8 \pm 2.1$ & $11.0 \pm 4.4$ & $24.7 \ddagger \pm 6.9$ & $3.3 \pm 1.4$ & $10.7 \pm 5.1$ & $8.4 \S \pm 3.4$ \\
\hline
\end{tabular}

* Mean values \pm SD for three recording sessions of $10 \mathrm{hr}$ in each dog starting $14 \mathrm{hr}$ after receiving canned food.

$\dagger$ As a percentage of the recording time.

中 Significantly different from ascending colon, $P<0.01$.

$\S$ Significantly different from intact dogs, $P<0.01$.

descending colon at $25 \mathrm{~cm}$ from the ileocolonic junction. The propagation of $20-40 \%$ of the LSBs in aboral direction at a speed of $2.4 \pm 0.5 \mathrm{~mm} / \mathrm{sec}$ was clearly observed between two electrode sites at less than $5-\mathrm{cm}$ intervals. The LSBs were grouped in periods lasting $4.9 \pm 2.0 \mathrm{~min}$ on the ascending colon at $2 \mathrm{~cm}$ from the junction; the duration of these periods increased progressively along the colon and reached $12.7 \pm 5.0 \mathrm{~min}$ on the descending colon at $25 \mathrm{~cm}$ from the junction. These periods of LSB activity recur cyclically at intervals of $28.4 \pm 9.0 \mathrm{~min}$ on all parts of the colon and occupied, respectively, $12.5,20.5$, and $22.9 \%$ of the recording time on the ascending, transverse, and descending colon (Table 1).

Short spike bursts lasted $1.0 \pm 0.3 \mathrm{sec}$ and also occurred in more or less regular series for periods of 10-25 min without cyclic organization. These periods occurred independently from the LSB phases, and no evident propagation of an SSB between two electrode sites $5 \mathrm{~cm}$ apart was observed. Of all the spike activities in the distal parts of the colon, SSB
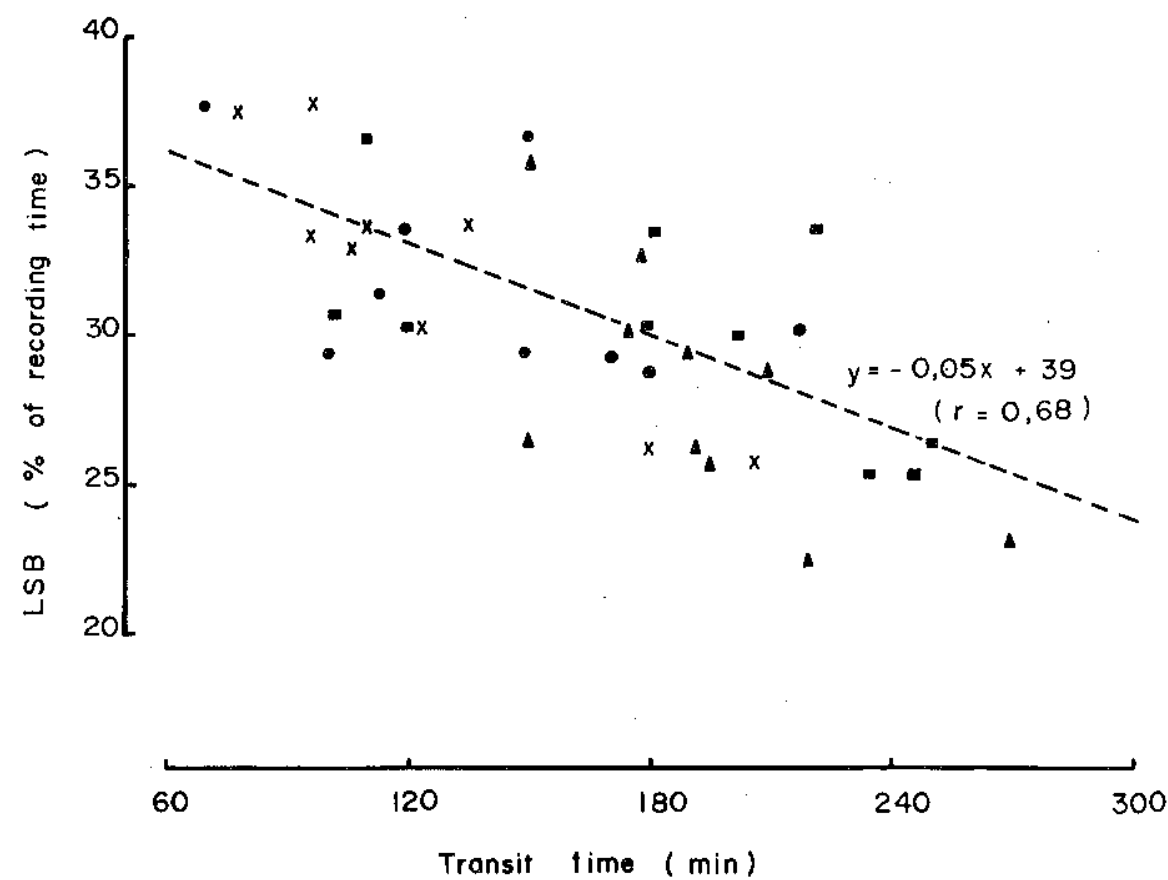

Fig 2. Relationships between the colonic transit time determined by PSP elimination curves and the percentage of the recording time of long spike bursts (LSB) in 4 colostomized dogs. Each value corresponded to a single experiment performed in one of the dogs designated by individual symbols. 
Table 2. Relationships between Electrical Spiking Activity of Transverse Colon and Fecal Output in Intact Dogs*

\begin{tabular}{|c|c|c|c|}
\hline & $\begin{array}{l}\text { Canned food } \\
\quad(\mathrm{N}=6)\end{array}$ & $\begin{array}{l}\text { Dry dog food } \\
\quad(\mathrm{N}=4)\end{array}$ & $\begin{array}{c}\text { Meat } \\
(\mathrm{N}=3)\end{array}$ \\
\hline \multicolumn{4}{|c|}{ Myoelectrical activity (\% of recording time) } \\
\hline Total spiking activity & $39.0 \pm 7.1$ & $51.7 \pm 8.2 \dagger$ & $51.1 \pm 3.9 \dagger$ \\
\hline Long spike bursts & $28.3 \pm 7.0$ & $47.6 \pm 11.0^{\dagger}$ & $9.5 \pm 6.2 \dagger$ \\
\hline Short spike bursts & $10.7 \pm 5.1$ & $4.1 \pm 0.9 \dagger$ & $41.6 \pm 9.0 \dagger$ \\
\hline LSB/SSB ratio & 2.6 & 11.6 & 0.2 \\
\hline \multicolumn{4}{|c|}{ Fecal output during recording periods } \\
\hline Stool consistency & Solid & Soft & Hard \\
\hline \multicolumn{4}{|l|}{ Weight of stools } \\
\hline daily amount (g) & $92.6 \pm .26 .1$ & $183.4 \pm 42.2 \dagger$ & $30.3 \pm 9.2 \dagger$ \\
\hline Dry matter & $21.0 \pm 2.4$ & $11.4 \pm 1.6+$ & $32.6 \pm 4.4 \dagger$ \\
\hline
\end{tabular}

*Mean values \pm SD for 3 recording sessions of $10 \mathrm{hr}$ in each dog, starting $14 \mathrm{hr}$ after receiving canned food, dry dog food, or meat.

$\dagger$ Significantly different from canned food, $P<0.01$.

activity was the predominant kind occupying $24.7 \pm$ $6.9 \%$ of the recording time vs $5.8 \pm 2.1$ and $11.0 \pm$ $4.4 \%$ on the ascending and transverse colon, respectively.

Effects of Colostomy. The myoelectrical activity of the colostomized dog differed only on two points from that observed in the intact dog. First, the LSB activity was greater on the distal part of the colon and the periods of LSB recurred more regularly on the descending colon as indicated by the low standard deviation shown in Table 1. Second, the descending colons of colostomized dogs had $65 \%$ less SSB activity (Table 1).

Patterns of Myoelectrical Activity Associated with Colonic Propulsion. Direct observation showed that the flow of colonic contents through the colostomy was intermittent, as small gushes of $5-17 \mathrm{~g}$ followed the development on the whole colon of a period of LSB activity. When a bolus of phenol red was injected into the proximal colon, the first colored feces appeared through the colostomy after about $60 \mathrm{~min}$, ie, after the development of 2-3 periods of LSB activity. Peaks of maximal concentration of the marker were recorded between 60 and $300 \mathrm{~min}$ after its injection, corresponding to $2-14$ periods of LSB activity. These fluctuations of the transit time in colostomized dog were significantly correlated to variations in the occurrence of LSB activity expressed as a percentage of the recording time (Figure 2). By contrast, the changes in the presence of SSB activity were not significantly related to the different variations of the transit time.

Effects of Diet. The onset of abundant and watery stools ( $11 \%$ dry matter vs $21 \%$ ) occurred within 48 $\mathrm{hr}$ in the 4 dogs which ingested all the dry food offered ( $440 \mathrm{~g}$ dry matter). The daily amount of stools, which was nearly doubled, averaged $183 \pm 42$ vs $92.0 \pm 26.1 \mathrm{~g}$ for canned food ( $87 \mathrm{~g}$ dry matter). This phenomenon was accompanied by a $23 \%$ increase of the total electrical spiking activity (Table 2 ). The LSB activity represented about $90 \%$ of this activity (Figure 3) at the expense of the SSB activity, so that the LSB/SSB ratio reached 11.6 vs 2.6 for canned food.

A reduced daily fecal output and hard feces ( 30.3 $\pm 9.2 \mathrm{~g}$ ) appeared after 2-4 days and during 10-12 days in 3 of the $6 \mathrm{dogs}$ offered $300 \mathrm{~g}$ of meat once a day. During this period, the total electrical spiking activity was increased by $23 \%$. The SSB activity represented $82 \%$ of this activity at the expense of LSB activity. This pattern occupied less than $10 \%$ of the recording time so that the LSB/SSB ratio diminished to 0.2 vs 2.6 for canned food. The last panel in Figure 3 shows the continuous uniform pattern in SSB activity. There was no apparent tendency of propagation from one electrode site to another.

\section{DISCUSSION}

The present study demonstrates the existence in dogs, as in humans (6) and pigs (7), of two major patterns of colonic spike bursts: LSB and SSB, and the relationships between LSB activity and propulsion of the large-bowel contents. In dogs, the LSBs are grouped in series recurring cyclically at $30-\mathrm{min}$ intervals and seemed propagated down along the colon as the "migrating spike bursts" in the cat (14). Like the migrating spike bursts of the cat colon in vitro (14), the LSBs observed in vivo in the dog are unrelated to the slow waves, despite their similar rate on the proximal colon only. The periods of LSB activity were similar in frequency and duration 

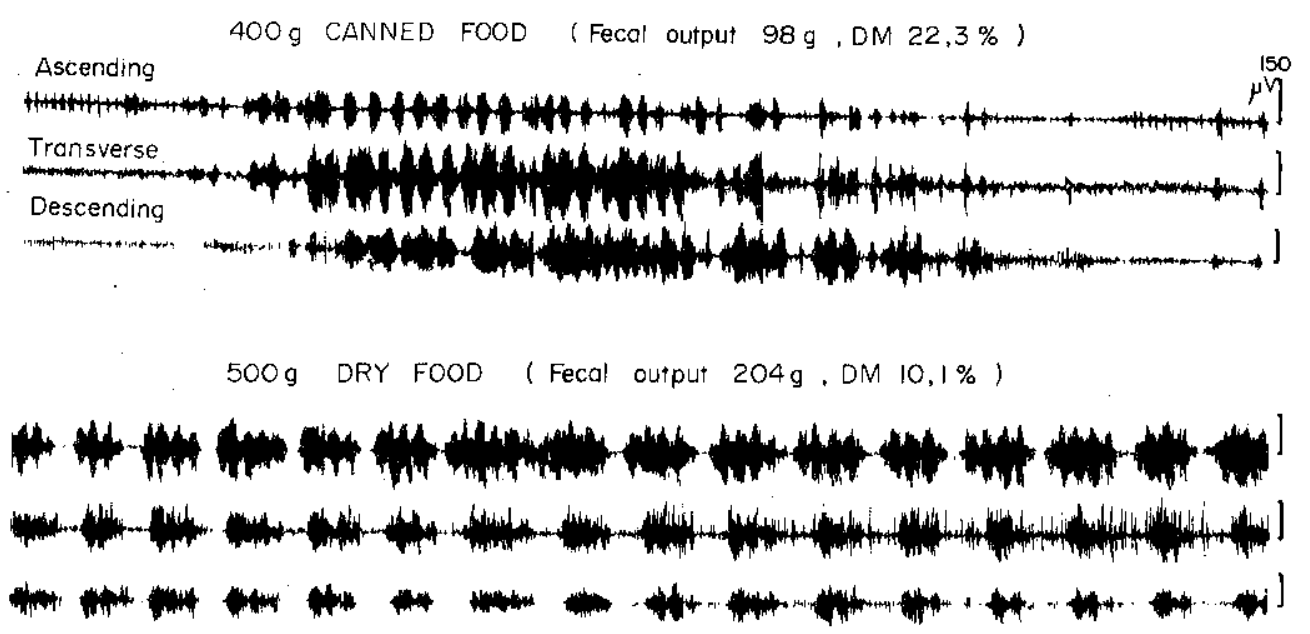

$300 \mathrm{~g}$ MEAT (Fecal output $24 \mathrm{~g}$, DM $35,2 \%$ )

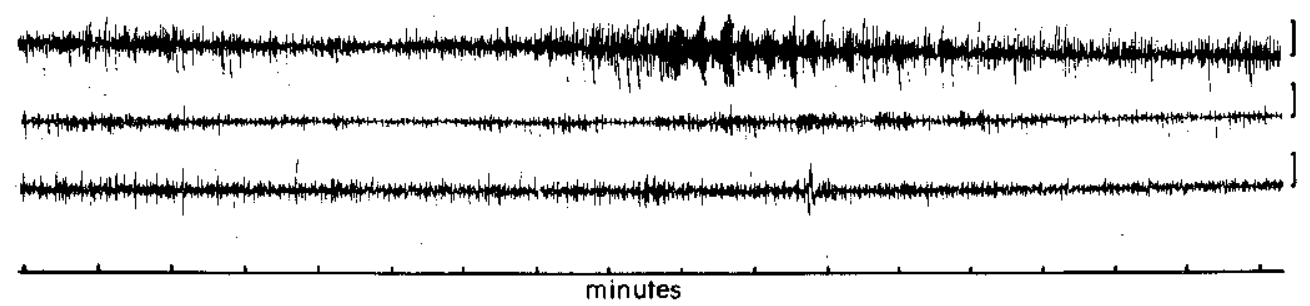

Fig 3. Patterns of colonic myoelectrical activity recorded from three electrode sites on the ascending, descending and transverse colon at, respectively 5,25 , and $15 \mathrm{~cm}$ from the ileocolonic junction, in a dog receiving canned food $(400 \mathrm{~g})$, a large amount $(500 \mathrm{~g})$ of dry cereal-rich food, or only meat $(300 \mathrm{~g})$. The values in parentheses indicate the fecal output and the dry matter (DM) of the feces measured on the day of the record presented.

to the phases of high colonic pressure recorded in both proximal and distal canine colon by Adler and Templeton 40 years ago and associated with propulsion of the large-bowel contents (15). Their presumed electrical equivalent (the periods of LSB activity) were found here to be negatively correlated with transit time. These results are in agreement with those obtained in pigs for which a decrease of the dietary fiber was associated with a lengthened transit time and a reduced number of LSBs (7).

Another point to be mentioned is that the total electrical spiking activity was increased in both low and high fecal output induced by dietary changes. Watery stools were obtained in dogs which ingested large amounts of dry dog food. The increase in colonic electrical spiking activity is mainly that of LSB activity involved in the propulsion of a large amount of stools. However, such effects are not in accordance with the low-amplitude pressure waves
(9) and the reduced spiking activity of the distal colon (6) observed in chronic diarrhea in man. They must therefore be considered in carnivores like dogs as the result of unusual feeding habits.

By contrast, the increase in SSB activity associated with the reduction of the fecal output and the production of hard feces induced by meat is similar to that observed in the human spastic colon which is associated with localized high pressures (9). This similarity suggests that the pathological records obtained in constipated patients may be only a consequence of the abnormal fecal output or colonic propulsion. Accordingly, the SSB activity may be associated with the production of hard feces as well as the consequence of colonic vacuity linked to a low-residue diet.

Finally, the total electrical activity of the colon was not an index of the colonic motor changes since it was greater with both low and high fecal output. 
By contrast, the LSB/SSB ratio reflects the volume of fecal output, the presence of LSBs being enhanced for an increased amount of soft feces whereas SSB activity predominates in the case of scarce and hard feces.

\section{ACKNOWLEDGMENTS}

This research was supported by I.N.R.A. (Animal Pathology Department).

\section{REFERENCES}

1. Caprilli R. Vernia P, Frieri G, Melchiorri P: Two electric rhythms in the colon. Rendic Gastroenterol 7:65-66, 1975

2. Mizhorokova Z, Papasova M: Unified rhythm of the slow wave of the small and large intestine in the ileocaecal region. CR Acad Bul Sci 29:1535-1538, 1976

3. Bueno L, Garcia-Villar R, Ruckebusch Y: Activité électrique du colon de chien éveillé. CR Acad Sci Ser D 285:1463-1466, 1977

4. Snape WH, Carlson GM, Cohen S: Colonic myoelectrical activity in the irritable bowel syndrome. Gastroenterology $70: 326-330,1976$

5. Christensen J, Weisbrodt NW, Hauser RL: Electrical slow wave of the proximal colon of the cat in diarrhea. Gastroenterology 62:1167-1173, 1972
6. Bueno L, Fioramonti J, Ruckebusch Y, Frexinos J, Coulom P: An evaluation of colonic myoelectrical activity in health and functional diseases. Gut (in press)

7. Fioramonti J, Bueno L: Motor activity in the large intestine of the pig related to dietary fibre and retention time. Br J Nutr 43:155-162, 1980

8. Ruckebusch Y, Fioramonti J: Colonic myoelectrical spiking activity: major patterns and significance in six different species. Zbl Vet Med 27:1-8, 1980

9. Connell A: The motility of the pelvic colon. II. Paradoxical motility in diarrhea and constipation. Gut 3:342-348, 1962

10. Waller SL: Differential measurement of small and large bowel transit time in constipation and diarrhoea. A new approach. Gut 16:372-378, 1975

11. Bueno L, Fioramonti J, Ruckebusch Y: Rate of flow of digesta and electrical activity of the small intestine in dogs and sheep. J Physiol London 249:69 85, 1975

12. Summers RW, Helm J, Christensen J: Intestinal propulsion in the dog. Its relation to food-intake and the migratory myoelectric complex. Gastroenterology .70:753-758, 1976

13. Ruckebusch $\mathrm{Y}$ : The electrical activity of the digestive tract of the sheep as an indication of the mechanical events in various regions. J Physiol London 210:857-882, 1970

14. Christensen J, Anuras S, Hauser RL: Migrating spike bursts and electrical slow waves in the cat colon: effects of sectionning. Gastroenterology 66:240-247, 1974

15. Adler HF, Templeton RD: Correlation of activity and transportation in colon of dog. Am J Physiol 128:514-520, 1940 